\title{
DEVELOPING A ROBUST GREEN SUPPLY CHAIN PLANNING OPTIMIZATION MODEL CONSIDERING POTENTIAL RISKS
}

\author{
*Mohamed Sayed Alashhab ${ }^{1,2}$ and Ehab A. Mlybari ${ }^{1}$ \\ ${ }^{1}$ College of Engineering and Islamic architecture, Umm Al-Qura University, Makkah, Saudi Arabia \\ ${ }^{2}$ Faculty of Engineering, Ain-Shams University, Cairo, Egypt
}

*Corresponding Author, Received: 05 April 2020, Revised: 23 April 2020, Accepted: 5 May 2020

\begin{abstract}
Planning of the green supply chain has a great effect on its performance and on the environment. In this paper, a robust green supply chain network planning optimization model has been developed considering potential risks to identify production, inventory and shipping method. Robustness has been considered in the customers' demands of multi-periods. The developed model aims to maximize the supply chain network profit, maximize customer service level, and minimize the transportation Green House Gases emissions to reduce the negative risks (threats) on the environment, enhance sustainability and raise the value for money gaining from the network for all stakeholders. The proposed mathematical model has been formulated using Mixed Integer Linear Programming and solved using three different solvers; Excel solver, evolver solver and @RiskOptimizer. The results have been discussed and analyzed in a manner to study the effect of robustness on the supply chain network behaviour. It can be concluded that the best optimal value has been achieved using Evolver solver plan which is the smoothest and the most practical.
\end{abstract}

KEYWORDS: Robust; Green supply chain; Production planning; Risks Management; Multi-objective; MILP; and Multi-periods

\section{INTRODUCTION}

It is not possible to expect many things very accurately because of the uncertainty that leads to risk [1]. Risk is an unavoidable phenomenon and affecting the system respective process, operations ...etc. [2]. SCM is one of the most important fields considered for reducing environmental impacts [3, 4]. Green supply chain management (GSCM) has been studied [5-7] in which every activity is consisting of various risks $[8,9]$. Supply chains were optimized with the general objective to minimize total costs [10], M. S. Al-Ashhab, N. Afia, and L. A. Shihata [11] studied the effect of the optimization objective on the SCN performance and concluded that optimizing the total cost has a bad effect on the performance of the business establishments. Sustainability issues are becoming more prevalent and environmental concerns are required to be addressed [12, 13].

The occurrence of risks may adversely impact the system if managers do not take them into consideration $[14,15]$. The management of GSC risks is still a gap [16]. Risks understanding and managing are very important for managers to reduce their consequences [17, 18]. Risks cause disruption or disturbance in the system [19]. So, it is necessary to include environmental aspects into SCM [20] especially those of negative impacts like resources, energy consumption and pollution. K. Hoen, T. Tan, J. Fransoo, and G. Van Houtum [21], E. Demir, T.
Bektaş, and G. Laporte [22], and C. Lin, K. L. Choy, G. T. Ho, S. H. Chung, and H. Lam [23] studied green transportation, S. Jain, E. Lindskog, J. Andersson, and B. Johansson [24] and Xie [25] focused on consumption of energy.

F. Wang, X. Lai, and N. Shi [26] studied an SCND problem with environmental concerns but they considered a single period model without inventory stored in each facility. In addition, other works that may be referred to are concerning supplier selection [27, 28], integrated modelling approaches [29, 30], and/or empirical case studies [31, 32]. An optimization model to select transportation modes, minimizing total costs, in addition, minimizing $\mathrm{CO}_{2}$ emissions has been suggested by Le and Lee [33]. A majority of transportation in the construction industry, and other industries, are completed by road (truck) transport [34].

F. Altiparmak, M. Gen, L. Lin, and T. Paksoy [35] formulated a multi-objective MINL model for a single product SCND. A multi-objective model to solve the problem of SC design taking into account demand satisfaction, the NPV, and financial risk was developed by G. Guillén, F. Mele, M. Bagajewicz, A. Espuna, and L. Puigjaner [36]. Liu and Papageorgiou [37] used a multi-objective MILP formulation in studying the production, capacity planning, and distribution of SCs. M. El-Sayed, N. Afia, and A. ElKharbotly [38] developed a multi-period multi- 
echelon forward-reverse logistics network design under risk model maximizing the total expected profit.

The aim of the present study is to investigate a robust green supply, a robust green supply chain network planning optimization model has been developed considering potential risks. Robustness has been considered in the customers' demands of multiperiods. The developed model aims to maximize network profit, maximize customer service level (CSL), and minimize the transportation gas emissions which can reduce the negative risks (threats) on the environment. These can enhance sustainability and raise the value for money gaining from the network for all stakeholders. The results have been discussed and analyzed in a manner to study the effect of robustness on the supply chain network behaviour. The proposed model has been solved using different solvers; Excel solver, evolver and @RiskOptimizer. This work is an extension of the work done by M. S. Al-Ashhab and E. A. Mlybari [39].

The system consists of one facility which is served by three potential suppliers to serve three potential customers as shown in Fig. 1.

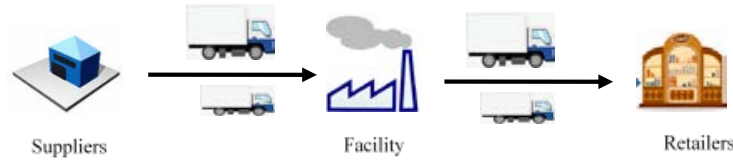

Fig. 1 Supply chain diagram [38].

The following assumptions have been considered:

1. The supply chain is single-product.

2. The supply chain is composed of three echelons; suppliers, factory and customers.

3. Customers' demands are robust and are assumed as normally distributed.

4. There are two types of trucks (Big and small).

5. Each type of trucks has a limited capacity.

6. Each truck should be fully loaded to be used.

7. Each truck should serve only one customer at the same trip.

8. The amount of $\mathrm{CO}_{2}$ gas emissions of the trucks is assumed to be constant and depends on the type and distance travelled.

9. The model considers three objectives; maximizing both profit and CSL while minimizing the gas emissions.

\section{MODEL FORMULATION}

In addition to the sets, parameters and variables mentioned in [40], the model involves the following: Sets:

M: Set of trucks.

Parameters:

CAPTMm: carrying capacity of truck $m$

GEmt: gas $\left(\mathrm{CO}_{2}\right)$ Emissions of truck $m$ per $\mathrm{km}$ in period $t$

TCmt: transportation cost of the transportation mode $m$ per kilometer in period $t$

DEMct: demand of customer $c$ in period $t$,

$\mu c t$ : demand mean of customer $c$ in period $t$,

$\sigma c t$ : demand standard deviation of customer $C$ in period $t$,

Decision variables:

Nmsft: The total number of mode m shipments from supplier $\mathrm{s}$ to the facility in period $\mathrm{t}$

Nmfct: The total number of mode m shipments from the facility to customer $\mathrm{c}$ in period $\mathrm{t}$

\subsection{Model Objectives}

There are three objectives have been considered through this developed model:

- Total Profit

- $\quad$ Customer Service Level (CSL)

- $\mathrm{CO}_{2}$ Emissions

\subsubsection{Total profit objective}

The profit is the difference between the total revenue calculated as in Eq. (1) and the total cost Eq. (4). The total cost is the summation of fixed, material, manufacturing, non-utilized capacity, back-ordering, transportation, and inventory holding costs calculated as shown in (4).

$$
\mathrm{TR}=\sum_{\mathrm{c} \in \mathrm{C}} \sum_{\mathrm{t} \in \mathrm{T}}\left(\left(\mathrm{Q}_{\mathrm{fct}}+\mathrm{I}_{\mathrm{fct}}\right) * \mathrm{~B}_{\mathrm{f}} * \mathrm{P}_{\mathrm{ct}}\right)
$$

\subsubsection{Customer Service Level Objective}

The CSL may be calculated as in (2).

$\mathrm{CSL}=\frac{\sum_{\mathrm{c} \in \mathrm{C}}\left(\left(\mathrm{Q}_{\mathrm{fct}}+\mathrm{I}_{\mathrm{fct}}\right) * \mathrm{~B}_{\mathrm{f}} * \mathrm{~W}\right)}{\sum_{\mathrm{c} \in \mathrm{C}}\left(\mathrm{DEM}_{c t} * \mathrm{~W}\right)}$ 


\subsection{3 $\mathrm{CO}_{2}$ Emissions}

The $\mathrm{CO}_{2}$ Emissions may be calculated as in (3).

$$
\begin{aligned}
C O_{2} \text { Emissions }= & \sum_{\mathrm{m} \in \mathrm{M}} \sum_{\mathrm{t} \in \mathrm{T}} \sum_{\mathrm{s} \in \mathrm{S}} \mathrm{N}_{\mathrm{msft}} * G E_{\mathrm{mt}} * \mathrm{D}_{\mathrm{sf}} \\
& +\sum_{\mathrm{m} \in \mathrm{M}} \sum_{\mathrm{t} \in \mathrm{T}} \sum_{\mathrm{c} \in \mathrm{C}} \mathrm{N}_{\mathrm{mfct}} * G E_{\mathrm{mt}} * \mathrm{D}_{\mathrm{fc}}
\end{aligned}
$$

$$
\begin{aligned}
& =\sum_{\mathrm{s} \in \mathrm{S}} \sum_{\mathrm{t} \in \mathrm{T}} \mathrm{Q}_{\mathrm{sft}} * \mathrm{~B}_{\mathrm{s}} * \text { MatCost }+\left(\mathrm{II}_{\mathrm{f}}-\mathrm{F}_{\mathrm{if}}\right) * \mathrm{~W} \\
& * \text { MatCost }+\sum_{\mathrm{c} \in \mathrm{C}} \sum_{\mathrm{t} \in \mathrm{T}}\left(\mathrm{Q}_{\mathrm{fct}}+\mathrm{I}_{\mathrm{fft}}\right) * \mathrm{~B}_{\mathrm{f}} * \mathrm{MH} * \mathrm{MC}_{\mathrm{ft}} \\
& +\left(\mathrm{II}_{\mathrm{f}}-\mathrm{F}_{\mathrm{if}}\right) * \mathrm{MH} * \mathrm{MC}_{\mathrm{ft}} \\
& +\sum_{\mathrm{t} \in \mathrm{T}}\left(\mathrm{CAPH}_{\mathrm{ft}}\right. \\
& \left.-\left(\sum_{\mathrm{c} \in \mathrm{C}}\left(\mathrm{Q}_{\mathrm{fct}}+\mathrm{I}_{\mathrm{fft}}\right) * \mathrm{~B}_{\mathrm{f}} * \mathrm{MH}\right)\right) * \mathrm{NUCC}_{\mathrm{f}} \\
& \left.+\sum_{\mathrm{c} \in \mathrm{C}}\left(\mathrm{DEM}_{\mathrm{c} 1}-\left(\mathrm{Q}_{\mathrm{fc} 1}+\mathrm{I}_{\mathrm{fc} 1}\right) \mathrm{B}_{\mathrm{f}}\right) * \mathrm{SCPU}\right) \\
& +\sum_{\mathrm{c} \in \mathrm{C}}\left(\sum_{\mathrm{g} \in 2 \ldots \mathrm{T}} \mathrm{DEM}_{\mathrm{c} 2}\right. \\
& \left.\left.-\sum_{\mathrm{g} \in 2 . . \mathrm{T}}\left(\mathrm{Q}_{\mathrm{fct}}+\mathrm{I}_{\mathrm{fct}}\right) * \mathrm{~B}_{\mathrm{f}}\right) * \mathrm{SCPU}\right) \\
& +\sum_{\mathrm{m} \in \mathrm{M}} \sum_{\mathrm{t} \in \mathrm{T}} \sum_{\mathrm{c} \in \mathrm{C}} \mathrm{N}_{\mathrm{mfct}} * \mathrm{~T}_{\mathrm{m}} * \mathrm{D}_{\mathrm{fc}}+\mathrm{II}_{\mathrm{f}} * \mathrm{~B}_{\mathrm{f}} * \mathrm{~W} * \mathrm{HF} \\
& +\sum_{\mathrm{t} \in(1-\mathrm{T})}^{\mathrm{R}_{\mathrm{ft}} * \mathrm{~B}_{\mathrm{f}} * \mathrm{~W} * \mathrm{HF}} \\
& +\mathrm{FCf}
\end{aligned}
$$

\subsection{Constraints}

There are two categories of constraints that have been taken into consideration in this model to ensure flow balancing and capacity limits

\subsubsection{Balancing constraints}

Constraint (5-9) are the flow balancing equations of materials and products.

$$
\begin{aligned}
& \sum_{\mathrm{s} \in \mathrm{S}} \mathrm{Q}_{\mathrm{sft}} * \mathrm{~B}_{\mathrm{s}}=\sum_{\mathrm{c} \in \mathrm{C}} \mathrm{Q}_{\mathrm{fct}} * \mathrm{~B}_{\mathrm{f}} * \mathrm{~W}_{\mathrm{p}}+\mathrm{I}_{\mathrm{fft}} * \mathrm{~B}_{\mathrm{f}} \\
& * \mathrm{~W}_{\mathrm{p}}, \forall_{\mathrm{t} \in \mathrm{T}} \\
& \mathrm{I}_{\mathrm{fft}} * \mathrm{~B}_{\mathrm{f}}+\mathrm{I}_{\mathrm{If}}=\mathrm{R}_{\mathrm{ft}} * \mathrm{~B}_{\mathrm{f}}+\sum_{\mathrm{c} \in \mathrm{C}} \mathrm{I}_{\mathrm{fct}} * \mathrm{~B}_{\mathrm{f}} \\
& \mathrm{I}_{\mathrm{fft}} * \mathrm{~B}_{\mathrm{f}}+\mathrm{R}_{\mathrm{ft}(\mathrm{t}-1)} * \mathrm{~B}_{\mathrm{f}}=\mathrm{R}_{\mathrm{ft}} * \mathrm{~B}_{\mathrm{f}}+\sum_{\mathrm{c} \in \mathrm{C}} \mathrm{I}_{\mathrm{fct}} * \\
& \mathrm{~B}_{\mathrm{f}}, \forall \mathrm{t} \in(2-\mathrm{T})
\end{aligned}
$$

$$
\mathrm{R}_{\mathrm{ft}} * \mathrm{~B}_{\mathrm{f}}=\mathrm{FI}_{\mathrm{f}}
$$$$
\left(\mathrm{Q}_{\mathrm{fct}}+\mathrm{I}_{\mathrm{fct}}\right) \mathrm{B}_{\mathrm{f}}
$$

$\leq \mathrm{DEM}_{\mathrm{ct}}$

$+\sum_{1 \rightarrow \mathrm{t}} \mathrm{DEM}_{\mathrm{c}(\mathrm{t}-1)}-\sum_{\mathrm{d} \in \mathrm{D}}\left(\mathrm{Q}_{\mathrm{fc}(\mathrm{t}-1)}+\mathrm{I}_{\mathrm{fc}(\mathrm{t}-1)}\right) \mathrm{B}_{\mathrm{f}}, \forall \mathrm{t}$

$\in \mathrm{T}, \forall \mathrm{c} \in \mathrm{C}$

\subsubsection{Capacity constraints}

Constraints (10-15) are the capacities equations.

$$
\begin{aligned}
& \mathrm{Q}_{\mathrm{sft}} * \mathrm{~B}_{\mathrm{s}} \leq \mathrm{CAP}_{\mathrm{st}}, \forall \mathrm{s} \in \mathrm{S}, \forall \mathrm{t} \in \mathrm{T} \\
& \sum_{\mathrm{s} \in \mathrm{S}} \mathrm{Q}_{\mathrm{sft}} * \mathrm{~B}_{\mathrm{s}} \leq \mathrm{CAPM}_{\mathrm{ft}}, \forall \mathrm{t} \in \mathrm{T} \\
& \left(\sum_{\mathrm{c} \in \mathrm{C}} \mathrm{Q}_{\mathrm{fct}} * \mathrm{~B}_{\mathrm{f}}+\mathrm{I}_{\mathrm{fft}} * \mathrm{~B}_{\mathrm{f}}\right) \mathrm{MH} \leq \mathrm{CAPH}_{\mathrm{ft}}, \forall \mathrm{t} \\
& \quad \in \mathrm{T} \\
& \mathrm{Q}_{\mathrm{sft}} * \mathrm{~B}_{\mathrm{s}}=\sum_{m \in M} \mathrm{CAPTM}_{\mathrm{m}} * \mathrm{~N}_{m s f t}, \forall \mathrm{s} \in \mathrm{S}, \forall \mathrm{t} \\
& \left(\mathrm{Q}_{\mathrm{fct}}+\mathrm{I}_{\mathrm{fct}}\right) * \mathrm{~B}_{\mathrm{f}} * \mathrm{~W}=\sum_{m \in M}\left(C A P T M_{m} *\right. \\
& \left.N_{m f c t}\right), \forall \mathrm{c} \in \mathrm{C}, \forall \mathrm{t} \in \mathrm{T} \\
& \mathrm{R}_{\mathrm{ft}} * \mathrm{~B}_{\mathrm{f}} * \mathrm{~W}_{\mathrm{p}} \leq \mathrm{CAPFS} \mathrm{st}_{1}, \forall \mathrm{t} \in \mathrm{T}
\end{aligned}
$$

\section{MODEL VERIFICATION}

The problem has been solved using different solvers; Excel solver, evolver and @RiskOptimizer to check the ability of the @RiskOptimzer to the solve it. Since Excel Evolver solver can solve only the deterministic problems and to make a comparison between the results of them with the results of @RiskOptimzer, the variability of demands will be reduced to Zero. The comparison has been made considering the profit optimization.

\subsection{Model Inputs}

Demands of each customer over the three periods are assumed as 11000, 10000, and 9000 units per period. Table 1 represents the model parameters while the assumed demands are shown in Table 1.

\subsection{Model Outputs and Analysis}

The model is solved using different solvers; Evolver, Excel, and @RiskOptimizer solvers on an Intel ${ }^{\circledR}$ Core ${ }^{\mathrm{TM}}$ i3-2310M CPU @2.10 GHz (3 GB of RAM). 
The results of the three solvers are presented and analyzed in this section.

Table 1 List of input parameters and their respective values

\begin{tabular}{lcc}
\hline Parameter & Value & \multicolumn{2}{c}{ Unit } \\
\hline S and C & 3 & -- \\
IIf & 500 & Unit \\
FIf & 1000 & Unit \\
Pct & 100 & $\$ /$ Unit \\
W & 1 & Kg \\
MH & 1 & Hrs \\
CAPst & 50000 & Kg \\
CAPHft & 12000 & Hrs \\
CAPMft & 10000 & Kg \\
CAPFSft & 2,000 & Kg \\
CAPTM & $300 \& 200$ & Kg/truck \\
MatCost & 10 & $\$ / \mathrm{kg}$ \\
MCft & 10 & $\$ / h r$ \\
MH & 1 & hrs \\
MCft & 10 & $\$ / h r$ \\
NUCCf & 5 & $\$ / h r$ \\
SCPU & 5 & $\$ /$ unit. \\
HC & 3 & $\$ / k g$. \\
Bs & 100 & Unit \\
Bf & 10 & Unit \\
FCmt & $0.02 \& 0.01$ & gallon $/ \mathrm{km}$ \\
GEmt & 3,2 & $\mathrm{~g} / \mathrm{km}$ \\
TCmt & $0.3 \& 0.2$ & $\$$ \\
FC & 50,000 & $\$$ \\
\hline & & \\
\hline
\end{tabular}

The optimal values of the three solvers are shown in Table 2 from which it can be concluded that the best optimal value has been achieved using Evolver solver plan which is the smoothest and the most practical as it is obvious from Tables 3-5. But the other optimal values obtained using Excel, and @RiskOptimizer solvers are also accepted where they have a small deviation as shown in Table 2. So, using @RiskOptimizer in optimizing this problem is accepted since its plan also achieves the same CSL as achieved by the other solvers as presented in Table 6 . Table 7 shows the transportation plan resulted from Evolver solver from which it is noticed that truck of type 2 has been used in most shipments because of its low cost while truck of type 1 has been used only for one trip to transfer the remaining quantities.
Table 2 Optimal values of the three solvers

\begin{tabular}{cccc}
\hline Solver & Evolver & Excel & @ Risk \\
\hline Total Profit & 1649705 & 1646799 & 1648571 \\
CSL & $100 \%$ & $99.8 \%$ & $99.9 \%$ \\
Deviation & $0 \%$ & $0.18 \%$ & $0.07 \%$ \\
\hline
\end{tabular}

Table 3 Evolver results

\begin{tabular}{|c|c|c|c|c|}
\hline & & \multicolumn{3}{|c|}{ Period } \\
\hline & Cust. & 1 & 2 & 3 \\
\hline \multirow{3}{*}{ 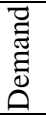 } & 1 & 11000 & 10000 & 9000 \\
\hline & 2 & 11000 & 10000 & 9000 \\
\hline & 3 & 11000 & 10000 & 9000 \\
\hline \multirow{3}{*}{$\underset{\substack{O \\
O}}{\cup}$} & 1 & 0 & 0 & 0 \\
\hline & 2 & 10000 & 10000 & 9000 \\
\hline & 3 & 0 & 0 & 0 \\
\hline \multirow{3}{*}{$\bigcup_{\text {王 }}^{\cup}$} & 1 & 0 & 0 & 0 \\
\hline & 2 & 500 & 0 & 0 \\
\hline & 3 & 0 & 0 & 0 \\
\hline \multirow{3}{*}{$\stackrel{\nexists}{\stackrel{\Xi}{\Xi}}$} & 1 & 0 & 0 & 0 \\
\hline & 2 & 10500 & 10000 & 9000 \\
\hline & 3 & 0 & 0 & 0 \\
\hline
\end{tabular}

Table 4 Excel Solver results in thousands

\begin{tabular}{|c|c|c|c|c|}
\hline & \multirow[b]{2}{*}{ Customer } & \multicolumn{3}{|c|}{ Period } \\
\hline & & 1 & 2 & 3 \\
\hline \multirow{3}{*}{ 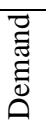 } & 1 & 11000 & 10000 & 9000 \\
\hline & 2 & 11000 & 10000 & 9000 \\
\hline & 3 & 11000 & 10000 & 9000 \\
\hline \multirow{3}{*}{$\underset{\sim}{\cup}$} & 1 & 0 & 0 & 0 \\
\hline & 2 & 10000 & 5800 & 5281 \\
\hline & 3 & 0 & 0 & 0 \\
\hline \multirow{3}{*}{ U } & 1 & 200 & 800 & 0 \\
\hline & 2 & 100 & 0 & 3719 \\
\hline & 3 & 0 & 3600 & 0 \\
\hline \multirow{3}{*}{ 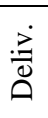 } & 1 & 200 & 800 & 0 \\
\hline & 2 & 10100 & 5800 & 9000 \\
\hline & 3 & 0 & 3600 & 0 \\
\hline
\end{tabular}

Table 5 @RiskOptimizer results

\begin{tabular}{|c|c|c|c|c|}
\hline & & \multicolumn{3}{|c|}{ Period } \\
\hline & Customer & 1 & 2 & 3 \\
\hline \multirow{3}{*}{ 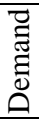 } & 1 & 11000 & 10000 & 9000 \\
\hline & 2 & 11000 & 10000 & 9000 \\
\hline & 3 & 11000 & 10000 & 9000 \\
\hline \multirow{3}{*}{$\underset{\sim}{\cup}$} & 1 & 9646 & 0 & 6348 \\
\hline & 2 & 0 & 0 & 193 \\
\hline & 3 & 0 & 0 & 0 \\
\hline \multirow{3}{*}{$\underset{\Theta}{\cup}$} & 1 & 854 & 9400 & 252 \\
\hline & 2 & 0 & 400 & 207 \\
\hline & 3 & 0 & 200 & 0 \\
\hline \multirow{3}{*}{ 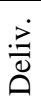 } & 1 & 10500 & 9400 & 6600 \\
\hline & 2 & 0 & 400 & 2400 \\
\hline & 3 & 0 & 200 & 0 \\
\hline
\end{tabular}


Table 6 Customer Service Level of the three solvers

\begin{tabular}{cccc}
\cline { 2 - 4 } & \multicolumn{3}{c}{ CSL } \\
\hline Customer & Evolver & Excel & @Risk \\
\hline 1 & $0 \%$ & $0 \%$ & $88 \%$ \\
2 & $98 \%$ & $98 \%$ & $9 \%$ \\
3 & $0 \%$ & $0 \%$ & $1 \%$ \\
\hline
\end{tabular}

Table 7 Transportation plan resulted from Evolver solver

\begin{tabular}{|c|c|c|c|c|}
\hline & & \multicolumn{3}{|c|}{ Period } \\
\hline & Customer & 1 & 2 & 3 \\
\hline 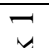 & 1 & 0 & 0 & 0 \\
\hline ป气 & 2 & 300 & 0 & 0 \\
\hline E & 3 & 0 & 0 & 0 \\
\hline$v$ & 1 & 0 & 0 & 0 \\
\hline 气્ّ & 2 & 10200 & 10000 & 9000 \\
\hline 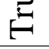 & 3 & 0 & 0 & 0 \\
\hline
\end{tabular}

\section{RESULTS AND DISCUSSIONS}

The problem has been solved using @RiskOptimizer and the results are presented and analyzed in this section. The demands are assumed as in the previous section in addition to assuming that the demands are normally distributed and their parameters are shown in Table 8. All demands are assumed to be normally distributed with a $10 \%$ variability. @RiskOptimizer supports around 83 types of distributions.

Table 8 Demands parameters

\begin{tabular}{llll}
\cline { 2 - 4 } & MIN & MEAN & MAX \\
\hline DEMCT11 & 8,119 & 11,001 & 13,978 \\
DEMCT12 & 7,164 & 9,997 & 12,477 \\
DEMCT13 & 6,379 & 8,995 & 11,304 \\
DEMCT21 & 8,169 & 11,001 & 13,962 \\
DEMCT22 & 7,583 & 10,000 & 12,441 \\
DEMCT23 & 6,545 & 9,001 & 11,421 \\
DEMCT31 & 8,022 & 11,001 & 13,915 \\
DEMCT32 & 7,469 & 10,000 & 12,450 \\
DEMCT33 & 6,783 & 9,001 & 11,578 \\
\hline
\end{tabular}

To verify the solving capability of the @RiskOptimizer, the problem has been solved four times to optimize different objectives; Total profit, CLS, $\mathrm{CO}_{2}$ emissions, and the summation of the three objectives (as a multi-objective with equally weighted objectives). The results of these four cases are tabulated in Table 9 from which it is clearly noticed that the results are logical. But the problem is that the Archimedean procedure used in the fourth case is not accepted because the three objectives do have the same units since the profit is in dollars, CSL is unitless, and $\mathrm{CO}_{2}$ emissions are in $\mathrm{kg}$. So, it is suggested to develop the model to optimize multi-objectives using the lexicographic procedure.

Table 9 Expected objectives values for the four cases

Optimized objective

\begin{tabular}{lcccc}
\hline Val & Profit & CSL & $\mathrm{CO}_{2}$ & $\mathrm{MO}$ \\
\hline Profit & 1648391 & 1607273 & -1165000 & 1645504 \\
$\mathrm{CSL}$ & $33 \%$ & $33 \%$ & $0 \%$ & $33 \%$ \\
$\mathrm{CO}_{2}$ & 224357 & 173876 & 0 & 2549 \\
\hline
\end{tabular}

Initially, profit, CLS, and $\mathrm{CO}_{2}$ emissions have been optimized individually and the resulted optimal distributions are depicted in Figs. 2, 3 \& 4 respectively. Finally, they have been optimized as a multi-objective using the Archimedean procedure and the results of optimization are depicted in Figs 5-8. Since, Fig. 5. shows the distribution of the optimal resulted equally weighted objectives summation while Fig. 6 presents the distribution of the optimal profit, Fig. 7 presents the distribution of the optimal CSL, and Fig. 8 presents the distribution of the optimal CO2 emissions.

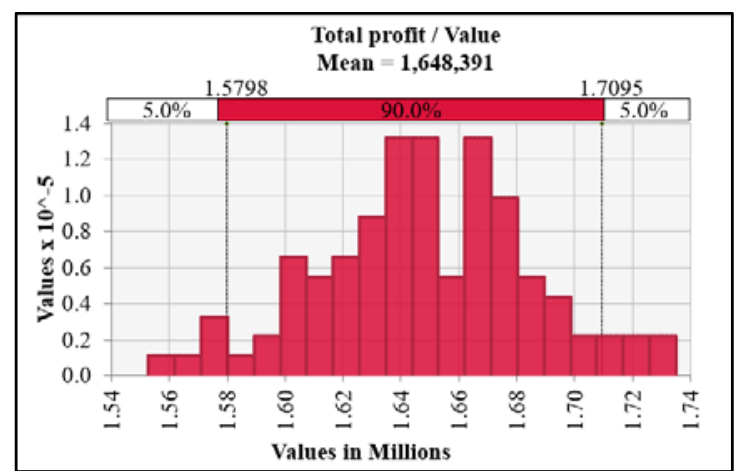

Fig. 2 Optimal resulted Total Profit distribution

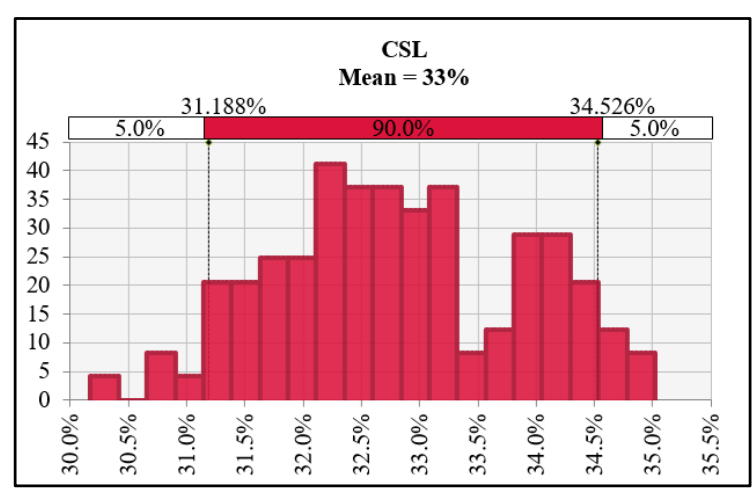

Fig. 3 Optimal resulted CSL distribution 


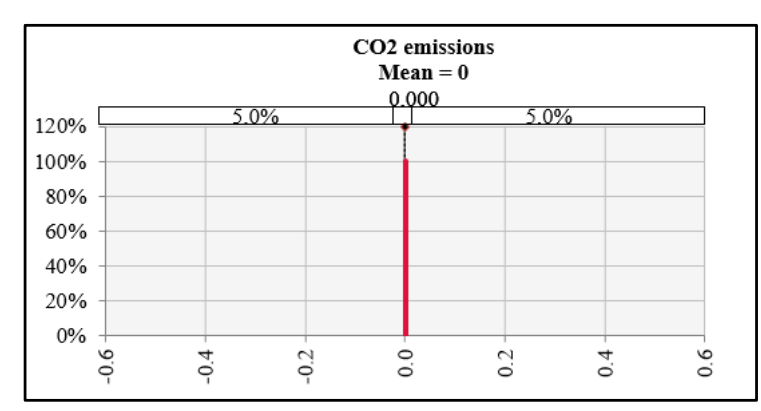

Fig. 4 Optimal resulted $\mathrm{CO}_{2}$ emissions distribution

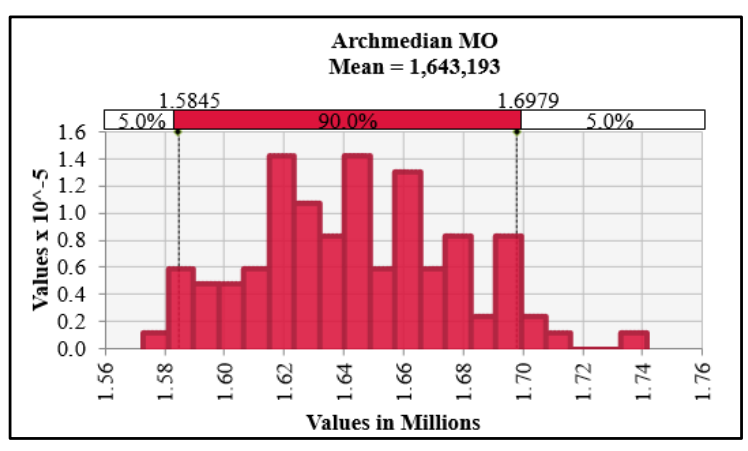

Fig. 5 Optimal objectives summation distribution

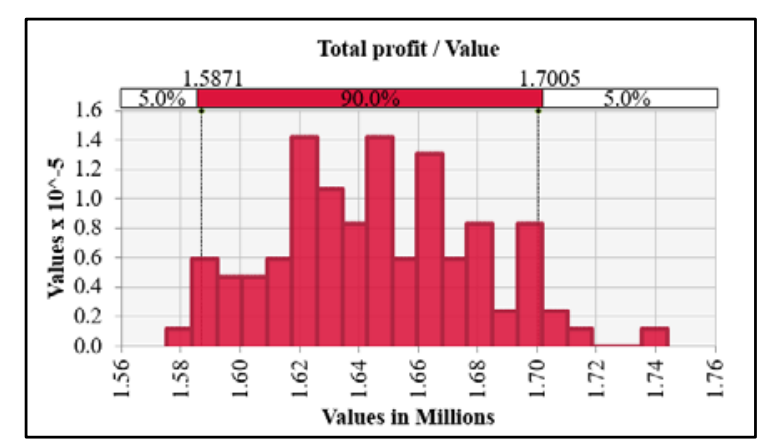

Fig. 6 Optimal resulted total profit distribution when optimizing objectives summation

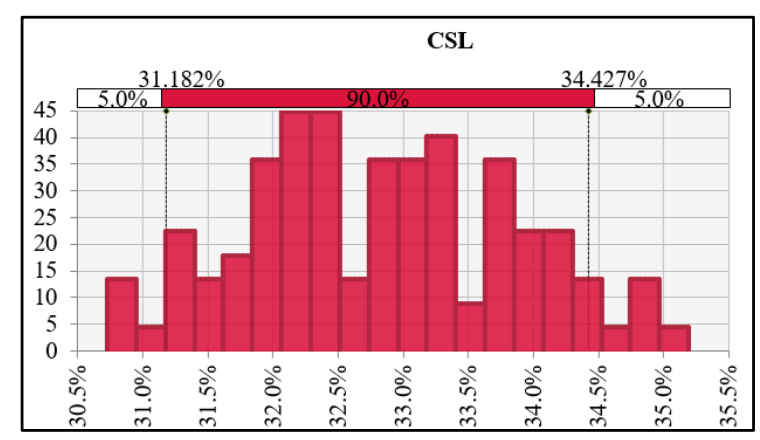

Fig. 7 Optimal resulted CSL distribution when optimizing objectives summation

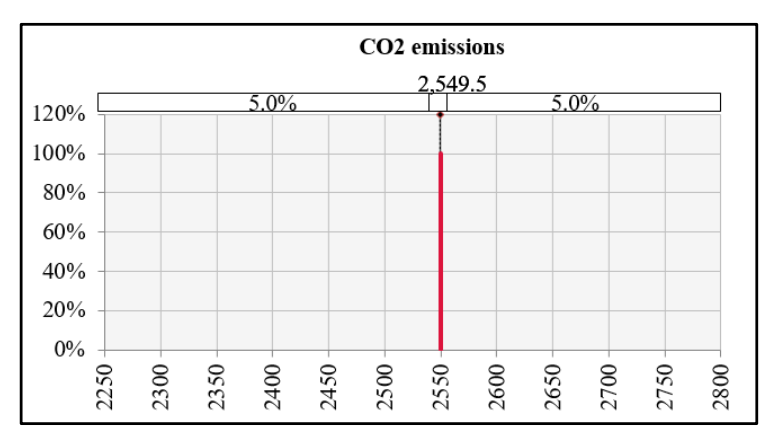

Fig. 8 Optimal resulted $\mathrm{CO}_{2}$ emissions distribution when optimizing objectives summation

\section{CONCLUSIONS}

In this research, a robust green supply chain network planning mathematical optimization model has been developed considering potential risks to identify production, inventory and shipping method. Robustness has been considered in the multi-period's customers' demands. The developed model successfully maximizes network profit, maximizes customer service level, and minimizes the transportation Green House Gases emissions which reduce the negative risks (threats) on the environment. These should enhance sustainability and raise the value for money gaining from the network for all stakeholders. But the problem is that the Archimedean procedure used in optimizing the summation of the three objectives (as a multi-objective with equally weighted objectives) is not accepted because the three objectives do have the same units since the profit is in dollars, CSL is unitless, and $\mathrm{CO}_{2}$ emissions are in $\mathrm{kg}$. So, it is suggested to develop the model to optimize multi-objectives using the lexicographic procedure.

\section{Future work:}

It is recommended to include:

1. the multi-product problem.

2. the uncertainty of other factors in addition to customers' demands.

3. different modes of transportations.

4. Each truck should serve more than one customer at the same trip.

5. Using the lexicographic procedure to optimize multi-objectives.

\section{ACKNOWLEDGEMENT}

The authors thank Perfect Building Contracting Establishment for its support to do this research. 


\section{REFERENCES}

[1] D. Waters, Supply chain risk management: vulnerability and resilience in logistics. Kogan Page Publishers, 2011.

[2] I. Manuj and J. T. Mentzer, "Global supply chain risk management strategies," International Journal of Physical Distribution \& Logistics Management, 2008.

[3] S. Mangla, J. Madaan, and F. T. Chan, "Analysis of performance focused variables for multiobjective flexible decision modeling approach of product recovery systems," Global Journal of Flexible Systems Management, vol. 13, no. 2, pp. 77-86, 2012.

[4] S. Mangla, P. Kumar, and M. K. Barua, "An evaluation of attribute for improving the green supply chain performance via DEMATEL method," International Journal of Mechanical Engineering \& Robotics Research, vol. 1, no. 1, pp. 30-35, 2014.

[5] S. K. Srivastava, "Green supply-chain management: a state-of-the-art literature review," International journal of management reviews, vol. 9, no. 1, pp. 53-80, 2007.

[6] L. Grandinetti, O. Pisacane, and $M$. Sheikhalishahi, "An approximate $\epsilon$-constraint method for a multi-objective job scheduling in the cloud," Future Generation Computer Systems, vol. 29, no. 8, pp. 1901-1908, 2013.

[7] S. Mangla, J. Madaan, P. Sarma, and M. Gupta, "Multi-objective decision modelling using interpretive structural modelling for green supply chains," International Journal of Logistics Systems and Management, vol. 17, no. 2, pp. 125-142, 2014.

[8] R. M. Ma, L. F. Yao, and R. Huang, "The green supply chain management risk analysis," in Advanced Materials Research, 2012, vol. 573, pp. 734-739: Trans Tech Publ.

[9] S. K. Mangla, P. Kumar, and M. K. Barua, "An integrated methodology of FTA and fuzzy AHP for risk assessment in green supply chain," International Journal of Operational Research, vol. 25, no. 1, pp. 77-99, 2016.

[10]C. H. Glock, "The joint economic lot size problem: A review," International Journal of Production Economics, vol. 135, no. 2, pp. 671686, 2012.

[11] M. S. Al-Ashhab, N. Afia, and L. A. Shihata, "Objective Effect on the Performance of a MultiPeriod Multi-Product Production Planning Optimization Model," International Journal of Mechanical \& Mechatronics Engineering IJMME-IJENS, vol. 16, no. 03, p. 13, 2016.

[12] M. Bonney and M. Y. Jaber, "Deriving research agendas for manufacturing and logistics systems: A methodology," International Journal of Production Economics, vol. 157, pp. 49-61, 2014.
[13] J. Sarkis, "A strategic decision framework for green supply chain management," Journal of cleaner production, vol. 11, no. 4, pp. 397-409, 2003.

[14] L. Qianlei, "The study on the risk management of agricultural products green supply chain based on systematic analysis," in 2012 Second international conference on business computing and global informatization, 2012, pp. 250-253: IEEE.

[15] S. K. Mangla, P. Kumar, and M. K. Barua, "A flexible decision framework for building risk mitigation strategies in green supply chain using SAP-LAP and IRP approaches," Global Journal of Flexible Systems Management, vol. 15, no. 3, pp. 203-218, 2014.

[16] S. K. Mangla, P. Kumar, and M. K. Barua, "Flexible decision approach for analysing performance of sustainable supply chains under risks/uncertainty," Global Journal of Flexible Systems Management, vol. 15, no. 2, pp. 113130, 2014.

[17]U. Jüttner, "Supply chain risk management," The international journal of logistics management, 2005.

[18] J. P. Vilko and J. M. Hallikas, "Risk assessment in multimodal supply chains," International Journal of Production Economics, vol. 140, no. 2, pp. 586-595, 2012.

[19] C. Harland, R. Brenchley, and H. Walker, "Risk in supply networks," Journal of Purchasing and Supply management, vol. 9, no. 2, pp. 51-62, 2003.

[20] M. Bonney and M. Y. Jaber, "Environmentally responsible inventory models: Non-classical models for a non-classical era," International Journal of Production Economics, vol. 133, no. 1, pp. 43-53, 2011.

[21]K. Hoen, T. Tan, J. Fransoo, and G. Van Houtum, "Effect of carbon emission regulations on transport mode selection under stochastic demand," Flexible Services and Manufacturing Journal, vol. 26, no. 1-2, pp. 170-195, 2014.

[22] E. Demir, T. Bektaş, and G. Laporte, "A review of recent research on green road freight transportation," European Journal of Operational Research, vol. 237, no. 3, pp. 775-793, 2014.

[23] C. Lin, K. L. Choy, G. T. Ho, S. H. Chung, and H. Lam, "Survey of green vehicle routing problem: past and future trends," Expert systems with applications, vol. 41, no. 4, pp. 1118-1138, 2014.

[24] S. Jain, E. Lindskog, J. Andersson, and B. Johansson, "A hierarchical approach for evaluating energy trade-offs in supply chains," International Journal of Production Economics, vol. 146, no. 2, pp. 411-422, 2013.

[25] G. Xie, "Modeling decision processes of a green supply chain with regulation on energy saving 
level," Computers \& Operations Research, vol. 54, pp. 266-273, 2015.

[26]F. Wang, X. Lai, and N. Shi, "A multi-objective optimization for green supply chain network design," Decision Support Systems, vol. 51, no. 2, pp. 262-269, 2011.

[27] A. Genovese, S. Lenny Koh, G. Bruno, and E. Esposito, "Greener supplier selection: state of the art and some empirical evidence," International Journal of Production Research, vol. 51, no. 10, pp. 2868-2886, 2013.

[28] L. Y. Lu, C. Wu, and T.-C. Kuo, "Environmental principles applicable to green supplier evaluation by using multi-objective decision analysis," International journal of production research, vol. 45, no. 18-19, pp. 4317-4331, 2007.

[29] S. Mirzapour Al-e-Hashem, A. Baboli, and Z. Sazvar, "A stochastic aggregate production planning model in a green supply chain: Considering flexible lead times, nonlinear purchase and shortage cost functions," European Journal of Operational Research, vol. 230, no. 1, pp. 26-41, 2013.

[30] B. Sundarakani, R. De Souza, M. Goh, S. M. Wagner, and S. Manikandan, "Modeling carbon footprints across the supply chain," International Journal of Production Economics, vol. 128, no. 1, pp. 43-50, 2010.

[31] J. L. Glover, D. Champion, K. J. Daniels, and A. J. Dainty, "An Institutional Theory perspective on sustainable practices across the dairy supply chain," International Journal of Production Economics, vol. 152, pp. 102-111, 2014.

[32] K.H. Lee, "Integrating carbon footprint into supply chain management: the case of Hyundai Motor Company (HMC) in the automobile industry," Journal of cleaner production, vol. 19, no. 11, pp. 1216-1223, 2011.

[33] T. P. N. Le and T.-R. Lee, "Model selection with considering the CO 2 emission alone the global supply chain," Journal of Intelligent Manufacturing, vol. 24, no. 4, pp. 653-672, 2013.

[34] M. Ö. A. Akan, D. G. Dhavale, and J. Sarkis, "Greenhouse gas emissions in the construction industry: An analysis and evaluation of a concrete supply chain," Journal of Cleaner Production, vol. 167, pp. 1195-1207, 2017.

[35]F. Altiparmak, M. Gen, L. Lin, and T. Paksoy, "A genetic algorithm approach for multiobjective optimization of supply chain networks," Computers \& industrial engineering, vol. 51, no. 1, pp. 196-215, 2006.

[36] G. Guillén, F. Mele, M. Bagajewicz, A. Espuna, and L. Puigjaner, "Multiobjective supply chain design under uncertainty," Chemical Engineering Science, vol. 60, no. 6, pp. 15351553, 2005.

[37] S. Liu and L. G. Papageorgiou, "Multiobjective optimisation of production, distribution and capacity planning of global supply chains in the process industry," Omega, vol. 41, no. 2, pp. 369382, 2013.

[38] M. El-Sayed, N. Afia, and A. El-Kharbotly, "A stochastic model for forward-reverse logistics network design under risk," Computers \& Industrial Engineering, vol. 58, no. 3, pp. 423431, 2010.

[39] M. S. Al-Ashhab and E. A. Mlybari, "A tactical multi-objective multi-product green supply chain planning optimization model," International Journal of Engineering \&Technology, vol. 7, no. 4, p. 8, 2018.

[40] M. S. Al-Ashhab, T. Attia, and S. M. Munshi, "Multi-Objective Production Planning Using Lexicographic Procedure," American Journal of Operations Research, vol. 7, no. 03, p. 174, 2017.

Copyright (C Int. J. of GEOMATE. All rights reserved, including the making of copies unless permission is obtained from the copyright proprietors. 